Following the first dose of NAC (100 mg/kg over 24 hours) four patients showed rapid clinical improvement of encephalopathy. Remaining three responded after second (2) and third (1) doses. In all seven patients, biochemical profiles showed improvement from first dose onwards (Figure). No side effects of NAC were noted. All seven made complete recovery without residual hepatic or neuro-developmental damage.

\section{Discussion}

Mild to moderate elevations in serum aminotransferase levels are common in dengue infections but ALF is a life-threatening complication for which there is no specific therapy and treatment is largely supportive. Cause of ALF in dengue infection is believed to be direct viral damage, dysregulated host-immune response or hypoxic damage [3]. Hypoxic damage is supported by the clinical observation of circulatory collapse which is a common association of ALF. In our series only three patients were exposed to prolonged shock.

NAC is of proven value in children with nonparacetamol induced liver failure. Its successful use in adults with ALF and severe dengue infection has been reported [4]. There is an isolated case report of its successful use in a child with fulminant liver failure complicating dengue infection [2]. In our series all seven children with ALF and severe dengue infection showed marked biochemical and clinical improvement following treatment with NAC. All patients made a full recovery with no residual liver damage. No adverse effects of NAC were encountered. This case series in a paediatric population supports the clinical observation that early administration of NAC in ALF complicating dengue infection results in a good outcome. We found NAC to be safe in this clinical situation.

\section{References}

1. Malavige GN. Pathogenesis of severe dengue infection. Ceylon Medical Journal 2012; 57: 97-100.

2. Lim G, Lee JH. N-acetylcysteine in children with dengueassociated liver failure: a case report. Journal of Tropical Pediatrics 2012; 58: 409-13.

3. Seneviratne SL, Malavige GN, de Silva HJ. Pathogenesis of liver involvement during dengue viral infections. Transactions of the Royal Society of Tropical Medicine and Hygiene 2006; 100: 608-14.

4. Ravindu SK, Mananjala SS, Krishan S, et al. Intravenous $\mathrm{N}$-acetylcysteine in dengue-associated acute liver failure. Hepatology International 2010; 4: 533-4.

\title{
Rate of stunting among a sample of postwar resettled families in the Vanni region: a study from the Mullaitivu District
}

\author{
R P J C Ramanayaka, R D N Sumanasekera, A H W de Silva, D P Perera, P Chandrasiri, R Gunasekera, \\ L R Jayasinghe
}

(Index words: nutritional deficiencies, stunting, chronic malnutrition)

\begin{abstract}
The Department of Family Medicine, University of Kelaniya conducted a health camp in Puthukudiyiruppu in March 2011. Height and weight measurements were carried out and data of 303 participants were analysed. The rate of stunting among children below six years in this population was $62 \%$ compared to $19.3 \%$ nationally. Thirty four percent of children and adolescents (6-18yrs) were underweight and $21.4 \%$ of adults had a BMI less than $18.5 \mathrm{~kg} / \mathrm{m}^{2}$.
\end{abstract}

Ceylon Medical Journal 2013; 58: 82-83

\section{Introduction}

The Department of Family Medicine, Faculty of Medicine, University of Kelaniya organised a health camp and goods donation campaign in Puthukudiyiruppu on 27th of March 2011 with the cooperation of the 14th Battalion of the Singha Regiment of the Sri Lanka Army.

Department of Family Medicine, Faculty of Medicine, University of Kelaniya, Sri Lanka.

Correspondence: RDNS, email: <rndeepama@gmail.com>. Received 20 July and revised version accepted 11 October 2012. Competing interests: none declared. 
Residents of the 3 villages Muthyankattukulam, Kanagarathnapuram and Mannakandal (population of approximately 550), who have been resettled in this area since February 2010, participated in the above event. Worldwide studies have shown high prevalence of nutritional problems among displaced populations [1]. This scenario presented an opportunity for a survey of anthropometric data in a community that has not been included in the national statistics for nearly three decades.

\section{Methods}

All attendees at the health camp were registered and their height and weight measurements were recorded by a medical officer as a routine screening process.

\section{Results}

A total of 408 had been registered for screening and data of 303 participants were available. Majority of participants were female (63.7\%). Forty six percent of the health camp attendees belonged to the age group of 19- 60 years.

Rate of stunting (height less than -2SD for age) among children below 6 years $(n=59)$ of age was $62.7 \%$ and a further $22 \%$ of the children were at risk of stunting. Weight for age was less than -2SD in 32.8\% of the children under 6 years of age whilst $42.2 \%$ were at risk with the weight being between -1SD to -2SD. Only $23.4 \%$ of the children were within the average weight of +2SD to -2SD. In this community, 34\% of children and adolescents between the ages of 6 to 18yrs ( $n=61$ ) were under weight (weight-for-age). In the adult population $(n=154)$ BMI was less than $18.5 \mathrm{~kg} / \mathrm{m}^{2}$ in $21.4 \%$, between $18.5 \mathrm{~kg} / \mathrm{m}^{2}$ to $24.9 \mathrm{~kg} / \mathrm{m}^{2}$ in $57.1 \%$ and over $25 \mathrm{~kg} / \mathrm{m}^{2}$ in $21.4 \%$.

\section{Discussion}

At the end of the three decade long armed conflict in Sri Lanka, resettlement processes are under way in the Northern and Eastern areas. This community was subject to many hardships during the war and the majority of inhabitants were of poor socio-economic status. In addition, the breakdown of health services, dependence on food aid and lack of a varied diet and fresh food compounded the health and nutritional problems. Height is considered an important indicator of nutrition and health of a population [2]. Stunting among children below 6 years of age in this population was $62 \%$, as compared to $19.3 \%$ nationally indicating that a large proportion is affected by chronic malnutrition [3]. Thirty four percent of children and adolescents (6-18yrs) and $21.4 \%$ of adults were underweight.

Many of the resettled communities in these regions could be having similar nutritional deficiencies. These problems are mainly due to rectifiable causes. If left unattended these could lead to irreversible consequences.

\section{References}

1. Cohen R, Deng FM. The forsaken people: case studies of the internally displaced. Brookings Institution Press; 1998: 372-3.

2. Akachi Y, Canning D. The height of women in sub-saharan Africa: the role of health, nutrition, and income in childhood. Annals of Human Biology 2007: 397-410.

3. Department of Census and Statistics in collaboration with Ministry of Health Care and Nutrition. Sri Lanka Demographic and Health Survey 2006/7. www.statistics.gov.lk 